\section{Psychotherapy and Psychosomatics}

Received: February 2, 2012

Accepted after revision: February 11, 2012

Published online: September 6, 2012

Psychother Psychosom 2012;81:378-379

DOI: $\underline{10.1159 / 000337200}$

\title{
A Clinimetric Evaluation of Allostatic Overload in the General Population
}

Elena Tomba, Emanuela Offidani

Laboratory of Psychosomatics and Clinimetrics, Department of Psychology, University of Bologna, Bologna, Italy

The concept of allostatic load represents the cost of the continual adjustment of the internal milieu required by the organism to adapt to different environmental demands [1]. The majority of studies on allostatic load have focused mainly on identifying its biological components, which are believed to mediate the relationship between stress and illness. Recently, according to the clinimetric approach [2], Fava et al. [3] introduced specific criteria for evaluating allostatic overload $(\mathrm{AO})$ in the clinical setting. $\mathrm{AO}$ refers to a state due to the cumulative interactions of life events and chronic life stressors that, by exceeding the individual's resources, may constitute a danger to health [3]. The first criterion deals with the specification of the stressor. Stress is measured by evaluating the occurrence of stressful situations in areas of major importance to the patient, resulting in major changes in the patient's living conditions, social and family circle, and work, as well as subtle and longstanding life situations, such as those occurring at work. In both cases the situation needs to be experienced by the individual as taxing or exceeding his/her coping skills. The second criterion is concerned with the clinical manifestations ranging from psychiatric to psychosomatic/subclinical symptoms, as defined by DSM-IV [4] and/or the Diagnostic Criteria for Psychosomatic Research (DCPR) [5], and from impairment in social and occupational functioning to decrease in wellbeing [6].

These criteria were shown to yield discrimination of biomarker profiles [7]. According to such criteria, individuals reporting AO presented lower levels of serum proteins, erythrocytes and immune differential count than subjects without AO [7].

Our study aims to evaluate the clinimetric feasibility of this new definition of AO in a sample of the general population. Specifically, our goal is to verify if such clinimetric criteria may discriminate not only among biological correlates, but also among psychometric variables.

Sixty-seven individuals recruited by advertisements in the general population participated in the study. Participants were evaluated using the following interviews: a structured interview based on clinimetric criteria for AO [3], the Structured Clinical Interview for DSM-IV for evaluating the presence of psychiatric diagnoses [8], the Clinical Interview for Depression (CID) for assessing symptoms related to depression and other psychiatric dis-

\section{KARGER}

Fax +41613061234 E-Mail karger@karger.ch www.karger.com
(C) 2012 S. Karger AG, Base $0033-3190 / 12 / 0816-0378 \$ 38.00 / 0$

Accessible online at: www.karger.com/pps orders [9], and the interview for the DCPR for measuring the presence of psychosomatic syndromes [5].

Subjects were asked to complete the Psychosocial Index, a selfrated questionnaire providing an appraisal of daily, work and interpersonal stress along with distress and psychological well-being [10].

A two-tailed Student's t test and $\chi^{2}$ were used to compare subjects with and without $\mathrm{AO}$ according to sociodemographic and psychiatric variables. Due to the exploratory nature of the study, Bonferroni's correction was not applied.

The sample consisted of 67 subjects ( 35 females and 32 males) recruited by advertisements. The age ranged from 22 to 59 years (mean $=38.24, \mathrm{SD}=12.01) ; 34.3 \%$ of the participants were married, $7.5 \%$ separated or widows and $58.2 \%$ unmarried. Concerning psychiatric variables, $14.9 \%$ of subjects $(n=10)$ were diagnosed with anxiety disorders (4 GAD, 3 social phobia, 2 panic and 1 agoraphobia), whereas about $45 \%(n=30)$ fulfilled the criteria for one or more DCPR syndromes (2 somatization conditions, 10 abnormal illness behavior and 18 type A behavior, demoralization or irritable mood).

Based on the clinimetric criteria [3], 29 individuals were evaluated as having AO. Results showed no differences between subjects with and without $\mathrm{AO}$ in sociodemographic variables and prevalence of anxiety disorders. Individuals reporting $\mathrm{AO}$ were more likely to present with DCPR syndromes $\left(\chi^{2}=3.96\right.$, d.f. $=1$, $p<0.05)$. Table 1 shows the clinimetric differences between the two samples. Patients with $\mathrm{AO}$ were found to have higher scores

Table 1. Mean differences between subjects with without $A O$ in CID and Psychosocial Index (PSI)

\begin{tabular}{lccc}
\hline AO & Mean \pm SD & t & $\mathrm{p}$ \\
\hline $\begin{array}{l}\text { CID total score } \\
\text { Yes (29) }\end{array}$ & & & \\
$\quad$ No (38) & $28.45 \pm 6.07$ & 3.34 & $<0.01$ \\
PSI distress & $24.08 \pm 3.92$ & & \\
$\quad$ Yes (29) & $6.07 \pm 3.72$ & 3.45 & $<0.001$ \\
$\quad$ No (38) & $3.29 \pm 2.55$ & & \\
PSI abnormal illness behavior & & & \\
$\quad$ Yes (29) & $0.76 \pm 1.24$ & 1.76 & $>0.05$ \\
$\quad$ No (38) & $0.32 \pm 0.62$ & & \\
PSI stress & & & \\
$\quad$ Yes (29) & $6.41 \pm 1.35$ & 4.65 & $<0.001$ \\
$\quad$ No (38) & $4.84 \pm 1.39$ & & \\
PSI well-being & & & \\
$\quad$ Yes (29) & $4.79 \pm 0.90$ & 2.93 & $<0.01$ \\
$\quad$ No (38) & $5.42 \pm 0.83$ & & \\
\hline
\end{tabular}

Elena Tomba, $\mathrm{PhD}$

Department of Psychology, University of Bologna

Viale Berti Pichat, 5

IT-40127 Bologna (Italy)

Tel. +39 051209 1823,E-Mail elena.tomba@unibo.it 
on the CID than those without it (table 1). In particular, subjects showing $\mathrm{AO}$ scored higher in fatigue $(\mathrm{t}=2.31$, d.f. $=65, \mathrm{p}<0.05)$, psychic and generalized anxiety $(t=2.00$, d.f. $=65, p<0.05)$, phobic anxiety $(\mathrm{t}=2.49$, d.f. $=38.13, \mathrm{p}<0.05)$, irritability $(\mathrm{t}=2.51$, d.f. $=42.21, \mathrm{p}<0.05)$, and initial insomnia $(\mathrm{t}=2.85$, d.f. $=38.58$, $\mathrm{p}<0.01)$. Subjects with $\mathrm{AO}$ also reported significantly higher levels of acute and chronic stress, psychological distress and significantly lower levels of well-being (table 1).

The study has obvious limitations due to its preliminary nature and the self-selecting nature of the sample. The clinimetric identification of $\mathrm{AO}$ was associated with depressive and anxiety symptoms, as well as impaired psychological well-being. CID scores revealed that $\mathrm{AO}$ individuals were more likely to report initial insomnia and to experience fatigue, irritability and anxiety symptoms. Previous reports have already shown that some items of the CID have been useful in identifying differential characteristics of depressed patients [8]. It has been shown that the generalized and phobic anxiety items significantly differentiated healthy controls from patients [8]. Similarly, the items of loss of energy and irritability significantly discriminated the presence of depression in patients whose depression were undiagnosed by their physician [8]. Interestingly, subjects who were identified by clinimetric criteria at the interview also displayed higher levels of both acute and chronic stress, as evaluated by the Psychosocial Index.

Clinimetric criteria may guide the clinical decision process by incrementally increasing the predictive power of the assessment procedure. Our results show that the clinimetric criteria for $\mathrm{AO}$, merging different clinical information otherwise assessed by several instruments, are able to discriminate the presence of distress. Such criteria may thus be considered a global index for detecting high-risk individuals for vulnerability to illness. The presence of AO calls for close monitoring of the patient's clinical state [3]. The fulfillment of such criteria may also detect conditions that may occur before an underlying medical or psychiatric disorder becomes noticeable. Thus, clinimetric indexes, more than diagnostic criteria, may help the clinician to identify important information and clinically relevant distress differences. Indeed, the ultimate goal of clinicians should be to prevent or decrease the negative impact of excessive stress on health.

\section{References}

1 McEwen BS, Stellar E: Stress and the individual. Mechanisms leading to disease. Arch Intern Med 1993;153:2093-2101.

2 Fava GA, Tomba E, Sonino N: Clinimetrics: the science of clinical measurements. Int J Clin Pract 2012;66:11-15.

-3 Fava GA, Guidi J, Semprini F, Tomba E, Sonino N: Clinical assessment of allostatic load and clinimetric criteria. Psychother Psychosom 2010; 79:280-284.

4 American Psychiatric Association: Diagnostic and Statistical Manual of Mental Disorders, ed 4. Washington, APA, 1994.

5 Fava GA, Freyberger HJ, Bech P, Christodoulou G, Sensky T, Theorell TT, Wise TN: Diagnostic criteria for use in psychosomatic research. Psychother Psychosom 1995;63:1-8.

6 Fava GA, Tomba E: Increasing psychological well-being and resilience by psychotherapeutic methods. J Pers 2009;77:1903-1934.

7 Offidani E, Ruini C: Psychobiological correlates of allostatic overload in a healthy population. Brain Behav Immun 2012;26:284-291.

8 First MB, Gibbon M, Spitzer RL, Williams JBW: User's Guide for the Structured Interview for DSM-IV Axis I Disorders. Research Version. New York, Biometrics Research, 1996.

9 Guidi J, Fava GA, Bech P, Paykel E: The Clinical Interview for Depression: a comprehensive review of studies and clinimetric properties. Psychother Psychosom 2011;80:10-27.

10 Sonino N, Fava GA: A simple instrument for assessing stress in clinical practice. Postgrad Med J 1998;74:408-410. 